\title{
NOTES ON GESTATION PERIODS AND LITTER SIZE IN THE ARENICOLOUS BUTHID SCORPION Leiurus quinquestriatus (EHRENBERG, 1828) (Scorpiones: Buthidae)
}

\section{Ross LK (1)}

(1) Member of the American Arachnological Society, American Entomological Society and International Society of Arachnology.

ABSTRACT: The following notes on gestation periods and litter size in seven specimens of Leiurus quinquestriatus are presented as observational data. Specimens of Leiurus quinquestriatus from southern Egypt and southern Israel were mated in the laboratory during 2007; afterwards, gestation periods and litter sizes of all females were recorded. Previous studies on this species reported that the gestation period ranged from 150 to 155 days and that litter size was between 12 and 99 offspring. In the present study, gestation periods in specimens from both geographic regions varied from 155 to 227 days and litter sizes were between 35 and 87 offspring. The current contribution expands on previously published data on gestation periods and supports previously reported litter size in Leiurus quinquestriatus.

KEY WORDS: scorpions, Buthidae, Leiurus quinquestriatus, gestation period, litter size.

CONFLICTS OF INTEREST: There is no conflict.

\section{CORRESPONDENCE TO:}

LUCIAN K. ROSS, 6303 Tarnow, Detroit, Michigan 48210-1558, USA. Phone: +1 313 285 9336. Email: lucian.ross@yahoo.com; Ikr@mail.org. 


\section{INTRODUCTION}

Attempts to explain present patterns of phylogeny, biogeography, ecology and biological diversity cannot be fully achieved without precise knowledge of the reproductive biology, postembryonic development and life history of scorpions (1). Species of the primarily cosmotropical family Buthidae C. L. Koch, 1836 are the most abundant and globally distributed of extant scorpions; occurring on all continents except Antarctica. Currently, the family Buthidae represents 81 (48.8\%) of the 166 described scorpion genera and 700 (46.7\%) of the approximately 1,500 described scorpion species (2). While all scorpions possess venoms, all but two of the approximately 30 to 50 medically significant species are members of the family Buthidae $(3,4)$. Due to their widespread geographic distribution, synanthropic habits and medical significance to large human populations in many tropical and subtropical regions, there has been greater interest and research conducted with buthid scorpions than with any other group $(1,5)$. However, a paucity of data exists regarding the life history and postembryonic development of the majority of buthid scorpions, with data reported for less than 40 (5.7\%) species $(1,5)$.

Leiurus quinquestriatus (Ehrenberg, 1828) (Buthidae) is a large (80 to $110 \mathrm{~mm} ; 1.0$ to $2.5 \mathrm{~g}$ ) and nocturnally active species that inhabits pre-existing spaces under rocks, abandoned burrows of other animals, or self-excavated burrows of $20 \mathrm{~cm}$ under rocks in arid and hyperarid regions of North Africa and the Middle East (6-12). Leiurus quinquestriatus venom is the most toxic reported among scorpion species (LD50: $0.25 \mathrm{mg} / \mathrm{kg}$ ), capable of provoking both dysfunction and failure of cardiovascular and respiratory systems (13-21). Neurotoxic venoms are particularly toxic to infants and young children, due to their weight-dependent effects (14). Whereas a large number of studies have been published on the biochemistry, toxicology and epidemiology of $L$. quinquestriatus and its venom, much less is known about its life history.

Heretofore, only a single study has provided data on the gestation of this scorpion species. Thornton (22) reported that the gestation period of a single $L$. quinquestriatus female from Sudan was 155 days while three additional specimens gestated for five months. Haseeb (23) registered a gestation period greater than 48 days for a Sudanese female. However, the short gestation period reported by this author indicated the number of days in captivity before the female gave birth (23). 
In contrast to scarce data regarding gestation, there have been numerous studies reporting $L$. quinquestriatus litter size that usually ranges from 12 to 99 individuals. In the aforementioned work, Haseeb (23) reported a single litter of 99 offspring for a Sudanese female. Similarly, Thornton (22) observed litter sizes of nine females from Sudan, which comprised from 41 to 82 young scorpions. Abushama (8) reported litters of 35, 38, 39 and 40 offspring from four Sudanese females. Additionally, Levy and Amitai (12) registered litter sizes of specimens from Israel, which ranged from 12 to 35. Based on previously published studies, L. quinquestriatus litter size varied between 12 and 99 offspring, while its gestation periods ranged from 150 to 155 days.

In March 2007, adult male $(n=6)$ and female $(n=4)$ specimens of $L$. quinquestriatus were acquired from field collectors in Aswan, southern Egypt. In April 2007, additional males $(n=2)$ and females $(n=3)$ were obtained from another field collector in southern Israel. Specimens from Egypt (Aswan desert) and Israel (Negev desert) were collected during the day from spaces and shallow chambers under rocks. During May 2007, females were randomly paired with males in specially prepared mating arenas. Courtship and mating behaviors of $L$. quinquestriatus have been reported by several authors $(8,9,22,24-26)$ and will not be discussed in the present study. After termination of mating sequences, all females were removed from mating arenas and maintained in $9.5 \mathrm{~L}$ glass enclosures (dimensions: $30 \times 12.5 \times 20 \mathrm{~cm}$ ), with a dry 5-6 cm layer of sand and a large fragment of terracotta plant pot to serve as retreat during periods of inactivity. Throughout the gestation period, females were maintained under a 14-hour-light/10-hour-dark cycle at constant temperatures of $27 \pm$ $1^{\circ} \mathrm{C}$. Relative humidity was not controlled and was estimated at $60 \pm 10 \%$ during the study period. Water was provided every 3 to 5 days by misting a small area of the enclosure wall, at and slightly above substrate level. Females received a single adult (18 to $25 \mathrm{~mm}$ ) common house cricket (Orthoptera: Gryllidae: Acheta domesticus L.) each week. Within a 45-day period, mesosomal distension was noted in all the seven mated females. After gestation periods of 155, 157, 159, 159, 217, 221 and 227 days $($ mean $=185$ days), females gave birth to litters of 35, 39, 54, 60, 81, and 87 (mean = 62.7) young. Based on the present study and references herein, it is possible to consider that Leiurus quinquestriatus gestation periods commonly range from 150 to 227 days. Litter size observed in the present study (35-87), in turn, corresponds to those already reported by previous authors. 
While the small sample size examined herein excludes statistical analysis, there appeared to be a correlation between female size and number of offspring produced, with larger females producing larger litters. Warburg and Elias (27) reported that $L$. quinquestriatus females from cooler and more mesic Mediterranean regions of northern Israel presented smaller average size $(1.0 \mathrm{~g})$ and produced fewer oocytes than did specimens of $L$. quinquestriatus $(2.0 \mathrm{~g})$ inhabiting warmer xeric regions of the south (e.g. Negev desert). It does not appear that a correlation exists between female size and size of individual offspring, with all females producing offspring of approximately the same size regardless the number produced in a litter. Based on limited personal observations reported in the present study, females of $L$. quinquestriatus appear to invest more reproductive energy into producing larger number of offspring, but not into producing larger offspring (27-28).

\section{ACKNOWLEDGMENTS}

I want to thank Juliana Simionato (JVATiTD) for her kindness and assistance to the author during the submission process, Jan Ove Rein (Norwegian Institute of Science and Technology, Trondheim, Norway) for supplying reference materials and three anonymous reviewers for their useful comments and suggestions on previous versions of the manuscript.

\section{REFERENCES}

1. Lourenço WR. Reproduction in scorpions, with special reference to parthenogenesis. In: Toft S, Scharff N, editors. European Arachnology 2000. Proceedings of the $19^{\text {th }}$ European Colloquium of Arachnology; 2000 July 17-22. Åarhus, Denmark. Åarhus: Åarhus University Press; 2002. p. 71-85.

2. Prendini L, Wheeler WC. Scorpion higher phylogeny and classification, taxonomic anarchy, and standards for peer review in online publishing. Cladistics. 2005;21(5):446-94.

3. Chippaux JP, Goyffon M. Epidemiology of scorpionism: a global appraisal. Acta Trop. 2008;107(2):71-9.

4. Ozkan O, Uzun R, Adiguzel S, Cesaretli Y, Ertek M. Evaluation of scorpion sting incidence in Turkey. J Venom Anim Toxins incl Trop Dis. 2008;14(1):128-40.

5. Polis GA, Sissom WD. Life history. In: Polis GA, editor. The biology of scorpions. Stanford: Stanford University Press; 1990. p. 161-223. 
6. Abushama FT. Bioclimate, diurnal rhythms and water-loss in the scorpion Leiurus quinquestriatus (H. \& E.). Entomol Mon Mag. 1964;98:216-24.

7. Abushama FT. On the behaviour and sensory physiology of the scorpion Leiurus quinquestriatus (H. \& E.). Anim Behav. 1964;12(1):140-53.

8. Abushama FT. Observations on the mating behaviour and birth of Leiurus quinquestriatus (H. \& E.), a common scorpion species in the Central Sudan. Rev Zool Bot Africaines. 1968;77:36-43.

9. Cloudsley-Thompson JL. Observations on the biology of the scorpion Leiurus quinquestriatus in the Sudan. Entomol Mon Mag. 1961;97:153-5.

10. Cloudsley-Thompson JL. The scorpion. Sci J. 1965;1:35-41.

11. Hadley NF. Adaptional biology of desert scorpions. J Arachnol. 1974;2:11-23.

12. Levy G, Amitai P. Fauna Palaestina. Arachnida I. Scorpiones. Jerusalem: The Israel Academy of Sciences and Humanities; 1980. p. 1-130.

13. Gueron M, Stern J, Cohen W. Severe myocardial damage and heart failure in scorpion sting. Report of five cases. Amer J Cardiol. 1967;19(5):719-26.

14. Gueron M, Yaron R. Cardiovascular manifestations of severe scorpion sting: clinicopathologic correlations. Chest. 1970;57(2):156-62.

15. Gueron M, Ovsyshcher I. What is the treatment of the cardiovascular manifestations of scorpion envenomation? Toxicon. 1987;25(2):121-4.

16. Gueron M, Ilia R, Sofer $\mathrm{S}$. The cardiovascular system after scorpion envenomation. A review. J Toxicol Clin Toxicol. 1992;30:245-58.

17. Ismail M. The scorpion envenoming syndrome. Toxicon. 1995;33(7):825-58.

18. Ismail M, Fatani AJ, Dabees TT. Experimental treatment protocols for scorpion envenomation: a review of common therapies and an effect of kallikrein-kinin inhibitors. Toxicon. 1992;30(10):1257-79.

19. Kopeyan C, Martinez G, Rochat H. Primary structure of toxin IV of Leiurus quinquestriatus quinquestriatus: characterization of a new group of scorpion toxins. FEBS Letters. 1985;181(2):211-7.

20. Shalita EA, Wells RD. Treatment of yellow scorpion (Leiurus quinquestriatus) sting: a case report. J Amer Pharm Assoc. 2007;47(5):616-9.

21. Sofer S, Gueron M. Respiratory failure in children following envenomation by the scorpion Leiurus quinquestriatus: hemodynamic and neurological aspects. Toxicon. 1988;26(10):931-9. 
22. Thornton JWB. Notes on the biology of Leiurus quinquestriatus (H. \& E. 1829). Brit J Anim Behav. 1956;4(3):92-3.

23. Haseeb MA. A scorpion in captivity. Sudan Not Rec. 1951;32:338.

24. Benton TG. Courtship and mating in Leiurus quinquestriatus (Scorpiones: Buthidae). In: Proceedings of a One Day Symposium on Spiders and Their Allies. UK: Chiron Publications Ltd.;1992. p. 83-98.

25. Shulov A. Observations on the mating habits of two scorpions, Leiurus quinquestriatus and Buthotus judaicus. Ent Soc Proc $10^{\text {th }}$ Int Congress Ent Montreal. 1958;1:877-80.

26. Shulov A, Amitai P. On the mating habits of three scorpions: Leiurus quinquestriatus H. and E., Buthotus judaicus E. Sim. and Nebo hierichonticus E. Sim. Arch Inst Pasteur d'Algerie. 1958;36(3):351-69.

27. Warburg MR, Elias R. Differences in the scorpion female reproductive system of Leiurus quinquestriatus $\mathrm{H} \& \mathrm{E}$ (Buthidae), in two populations inhabiting different zoogeographical regions in Israel. J Arid Environ. 1998;40(1):91-5.

28. Warburg MR, Elias R, Rosenberg M. Ovariuterus and oocyte dimensions in the female buthid scorpion, Leiurus quinquestriatus H. \& E. (Scorpiones: Buthidae), and the effect of higher temperature. Invert Reprod Develop. 1995;27(1):21-8. 